\title{
Mild separation system for olive oil: quality evaluation and pilot plant design
}

\author{
Francesco Genovese, Giovanni Carlo Di Renzo, Giuseppe Altieri, Antonella Tauriello \\ University of Basilicata, School of Agricultural, Forestry, Food \& Environmental Science (SAFE), \\ Potenza, Italy
}

\begin{abstract}
The entire process of olive oil extraction involves the breakage of olive fruits to obtain a paste, the kneading of the paste, a centrifugation, and a further cleaning, performed by a disc stack centrifuge, to separate the residual water. In this research, in order to evaluate the effect of final centrifugal separation on olive oil quality and to both define and design the settings of a innovative separation system, olive oil was separated off from water using an accelerated separation process, tested in comparison with a disc centrifuge. The laboratory plant used for the trials was constituted by a twin cylindrical separator equipped with 4 variable frequency inverters, in order to regulate the fluid flow rates in the plant. Oil samples were collected during the trials to evaluate the influence of the proposed innovative process on oil quality; measuring some parameters as free acidity, peroxides (PV), specific extinction coefficients $\mathrm{K}_{232}$ and $\mathrm{K}_{270}$, chlorophylls , carotenoids, total polyphenols (POL) and turbidity. Results showed statistically significant differences (p-values<0.05) in some parameters as POL, PV, and ultraviolet absorption K232 and K270.
\end{abstract}

\section{Introduction}

The final quality of olive oil, a vegetable oil obtained directly from olive fruits (Olea europea) and essential in the Mediterranean diet, is strictly related to some processing parameters (i.e. type of crusher, decanter geometry, added process water, malaxation time and temper-

Correspondence: Francesco Genovese, University of Basilicata, School of Agricultural, Forestry, Food \& Environmental Science (SAFE), Viale dell'Ateneo Lucano, 10, 85100 Potenza, Italy.

Tel. +39.0971.205256 - Fax: +39.0971.204322.

E-mail: francesco.genovese@unibas.it

Key words: vertical centrifugation, virgin olive oil quality, separation.

The authors contributed equally.

The authors declare no potential conflict of interests.

(C) Copyright F. Genovese et al., 2013

Licensee PAGEPress, Italy

Journal of Agricultural Engineering 2013; XLIV(s2):e61

doi:10.4081/jae.2013.s2.e61

This article is distributed under the terms of the Creative Commons Attribution Noncommercial License (by-nc 3.0) which permits any noncommercial use, distribution, and reproduction in any medium, provided the original author(s) and source are credited. ature). The process generally consists of four phases: (a) breakage of olive fruits (carried out by several type of crushers) producing a paste composed by a mixture of two distinct liquid phases (raw oil and water); (b) kneading of the paste, in order to facilitate cohesion of smaller oil droplets into larger ones; (c) centrifugation, to separate the different phases, which occurs in a horizontal screw conveyor centrifuge with continuous discharge of solid phase (decanter); (d) oil cleaning.

After extraction using decanter, the oil yet contains a small amount of residual water and impurities, requiring a further cleaning, that is performed by washing the oil in a vertical centrifuge with lukewarm tap water added (Di Giovacchino et al., 2002), which could produce negative effects on the quality (loss of aroma) and loss of stability of the final product (oxidative reactions), mainly due to oil heating and amount of dissolved oxygen (Masella et al., 2009).

Considering the latest developments (Amirante P. and Catalano, 1993; Amirante R. and Catalano, 2000; Catalano et al., 2003; Daou et al., 2007; Boncinelli et al., 2009; Altieri, 2010) in decanter centrifuge design, modeling and construction that allow the production of a cleaner oil both in terms of suspended solid and water content, the use of vertical disc stack centrifuge separator could result excessive; moreover in recent years there is an increasing interest in cloudy (veiled) extra-virgin olive oil since it is considered less processed by some consumers (Del Giovine et al., 2005; Koidis et al., 2008).

In this paper authors, evaluating some chemical and physical attributes of olive oil, propose a mild separation system for its cleaning; collected data allow to define the design parameters of a prototype system based on natural sedimentation in comparison with traditional centrifugal separation used to clean the raw oil (after the decanter extraction).

\section{Materials and methods}

The experimental trials were carried out using a laboratory plant, based on a gravity separating system, constituted by a twin cylindrical oil-water separator (two cylindrical columns connected in series). Each cylindrical column (made of transparent material suitable for contact with olive oil) was $2 \mathrm{~m}$ high $(0.27 \mathrm{~m}$ internal diameter, $0.29 \mathrm{~m}$ external diameter), and has a total volume of about $114 \mathrm{dm}^{3}$.

In order to balance the inlet flow rate to the outlet flow rate of both clean oil and oily deposits 4 volumetric pumps (2 for each column) with flexible impeller were used, controlled by a variable frequency inverter drive (VFD).

Raw oil, extracted from olive variety "Coratina" by decanter separation, was fed into the first column with a constant rate of about 1 $\mathrm{dm}^{3} / \mathrm{min}$. After about $90 \mathrm{~min}$, considering the columns internal volume, the raw oil leaves a sediment on the bottom of the column that is composed by high density suspended solids and residual water, while cleaned oil and low density suspended solids float to the surface of the 
cylinder. Cleaned oil extracted by the second pump, very close to the surface level ( $4 \mathrm{~cm}$ under the free surface level), was transferred into the second column, at a constant rate equal to the inlet. Maintaining constant the oil inlet and the outlets in the two columns, after the settling time of about 180 min, clean oil resulted about $90 \%$, while the residual dirty oil mixed with the water and settled materials was treated in a centrifugal separator.

In order to define the design criteria of the innovative plant prototype, oil samples were collected after the following processing operations: 1) extraction by centrifuge, the sample were collected on decanter exit (Control); 2) improved natural settling (sedimentation) performed in a laboratory plant (Sedoil); 3) centrifuge separation performed in a vertical disc stack centrifuge that represents the traditional oil cleaning operation (Cenoil).

Nine samples of olive oils were analyzed (within 48 hours after the treatment) for each treatment and for each sample composition, Sedoil and Cenoil samples were evaluated with reference to Control.

The non parametric Kruskal-Wallis test with Scheffe procedure was performed on the relative differences setting the multiple comparison post-hoc tests at $10 \%$ familywise error rate level.

\section{Analytical methods}

Free acidity (FA), peroxide value (PV), UV specific extinction coefficients (K232, K270) were determined according to the analytical method of the European Official Method of Analysis (EU Regulations 2568/91).

FA was determined by titration of a mixture of oil in ethanol/ether 1:2 (v/v) with potassium hydroxide $0.1 \mathrm{~N}$. PV was determined as follows: a mixture of oil and chloroform/acetic acid 2:3 (v/v) was left to react in darkness with a saturated potassium iodine solution; the released free iodine was titrated with a sodium thiosulphate solution $(0.01 \mathrm{~N})$.

K232 and K270 extinction coefficients were calculated from absorption at 232 (K232) and $270 \mathrm{~nm}$ (K270), respectively, with a spectrophotometer (UV/Nis Spectrophotometer, Ultraspec 2100 pro) using isooctane as a blank.

Chlorophylls (CHLO) and carotenoids (CAR) concentrations were spectrophotometrically determined fixing the wave length at $670 \mathrm{~nm}$ and $470 \mathrm{~nm}$ respectively, in hexane. The maximum absorption at 670 $\mathrm{nm}$ is related to the chlorophyll fraction, while the maximum absorption at $470 \mathrm{~nm}$ is related to the carotenoid fraction. The values of the applied coefficients of specific extinction were E0 $=613$ for pheophytin, a major component in the chlorophyll fraction, and E0 $=2000$ for lutein, a major component in the carotenoid fraction.

Total polyphenols (POL) contents were evaluated by a spectrophotometric method. Phenolic compounds were isolated by a double extraction of oil (10 g) with a methanol-water mixture $(80: 20 \mathrm{v} / \mathrm{v})$. The FolinCiocalteau reagent was added to a suitable aliquot of the extracts, and the absorption of the solution at $765 \mathrm{~nm}$ was measured. Gallic acid standard solutions were used to calibrate the method (linear concentration interval $15-500 \mathrm{mg} / \mathrm{dm}^{3}$ ). Turbidity measurements (TUR) were carried out by the nephelometric method with a Turbidimeter Model (Delta Ohm HD25.2) The turbidimeter used in the study was carefully calibrated with formazin standards (0.05-800 NTU).

\section{Results and discussion}

In Table 1 are shown the results obtained performing the chemical and spectrometric analysis associated with the collected data.

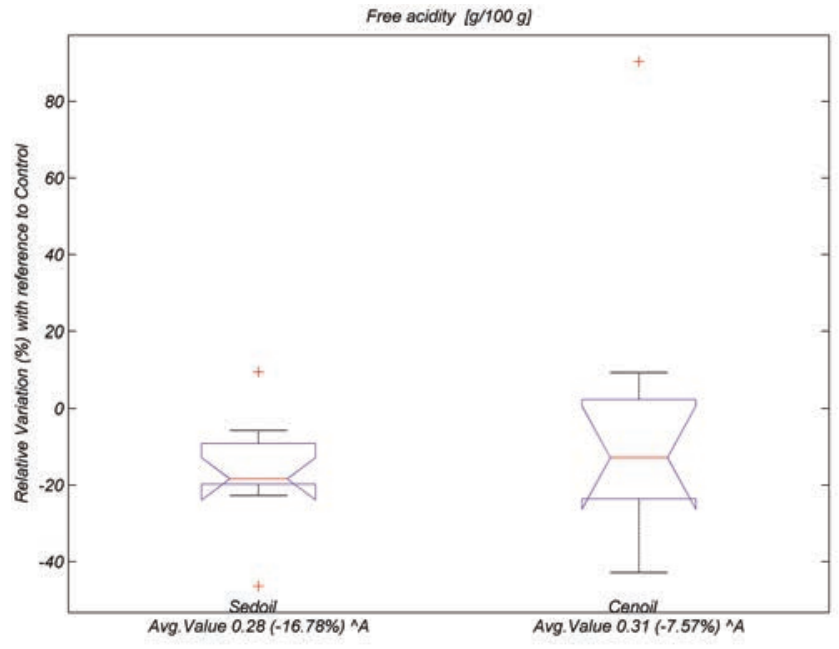

Figure 1 . Free acidity values box plot of relative difference with reference to Control.

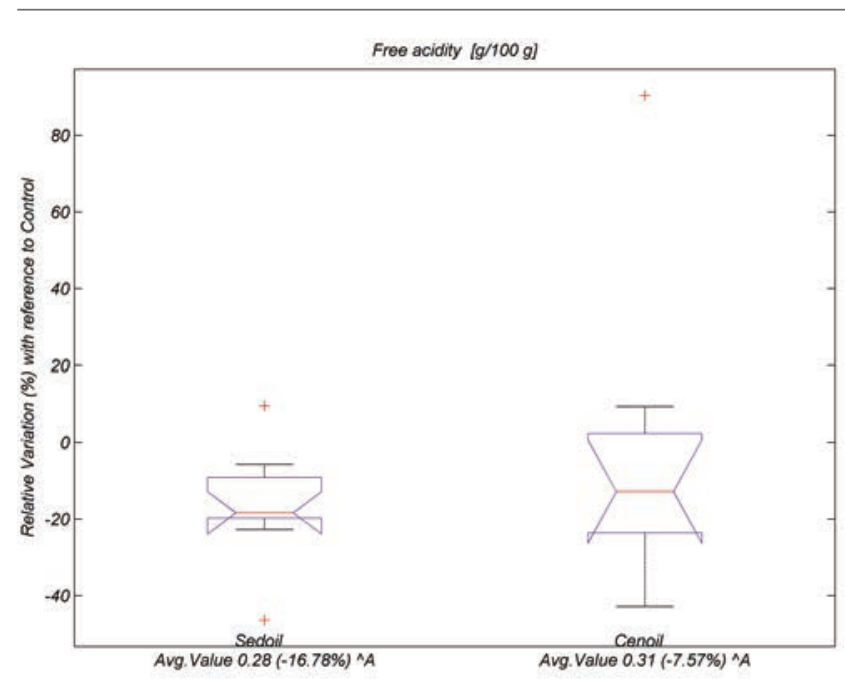

Figure 2. Peroxide values box plot of relative difference with reference to Control.

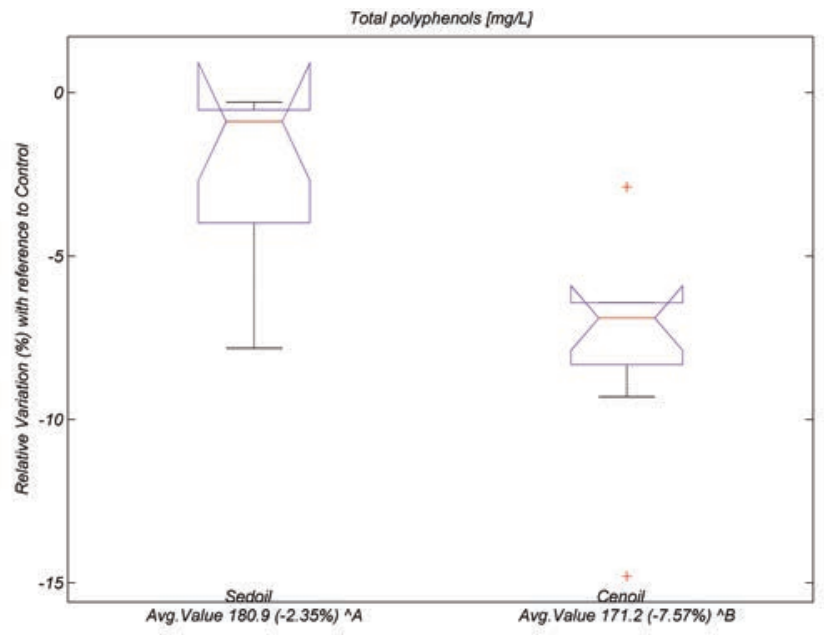

Figure 3. Total polyphenols values box plot of relative difference with reference to Control. 
Measured average water content was $0.9 \%$ and $0.7 \%$ in Sedoil and Cenoil respectively. The values did not result significantly different when referred to Control, thus proving that using the enhanced sedimentation process allows achieving an efficient water separation with a reduction of water content of $69.56 \%$.

Further, the measured oil temperature results significantly different between Sedoil and Cenoil; Sedoil treatment causes a temperature reduction from $33.3^{\circ} \mathrm{C}$ to $29.8^{\circ} \mathrm{C}$ with a reduction of $10.42 \%$. Cenoil treatment causes a temperature average value of $34.0{ }^{\circ} \mathrm{C}$ that represents an increase of the olive oil temperature $(+2.10 \%)$ after the extraction by decanter centrifuge.

In most cases the analysis of data shows that the value of each parameter evaluated in the Sedoil is not significantly different from the corresponding value in the raw olive oil obtained from decanter (Control), while the value of the same parameter in the Cenoil resulted significantly different: this demonstrates that the final centrifugal separation of raw olive oil from water and suspended solids by disc stack centrifuge produces modifications of the olive oil quality parameters respect to natural settling.

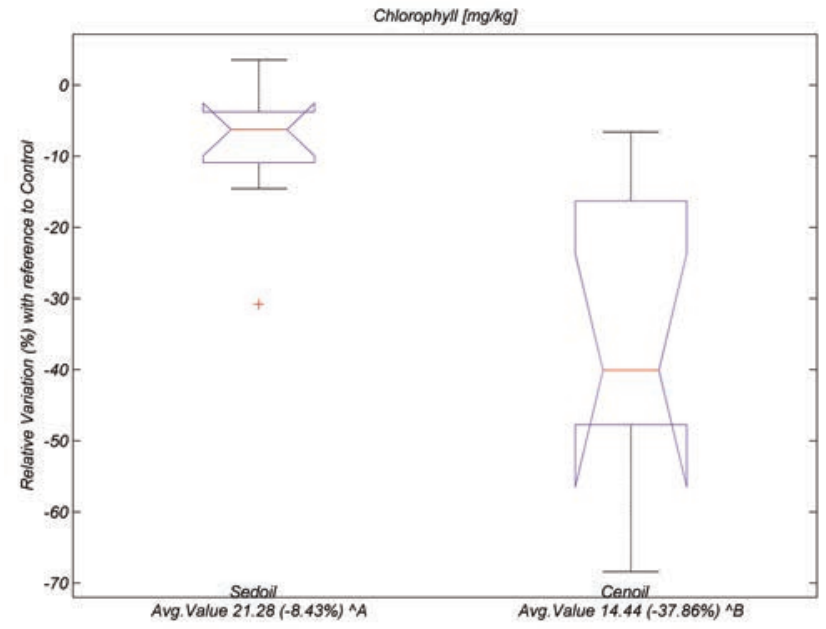

Figure 4. Chlorophyll values box plot of relative difference with reference to Control.

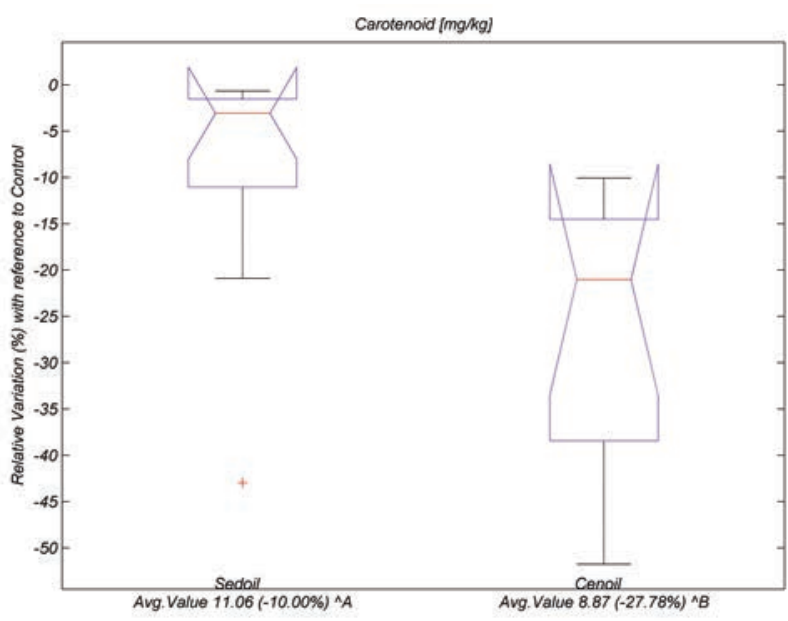

Figure 5. Carotenoid values box plot of relative difference with reference to Control.

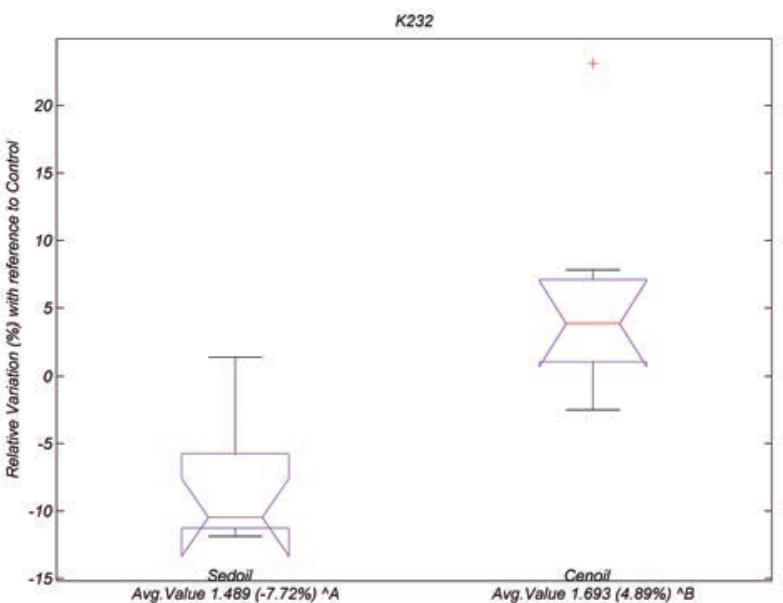

Figure 6. K232 values box plot of relative difference with reference to Control.

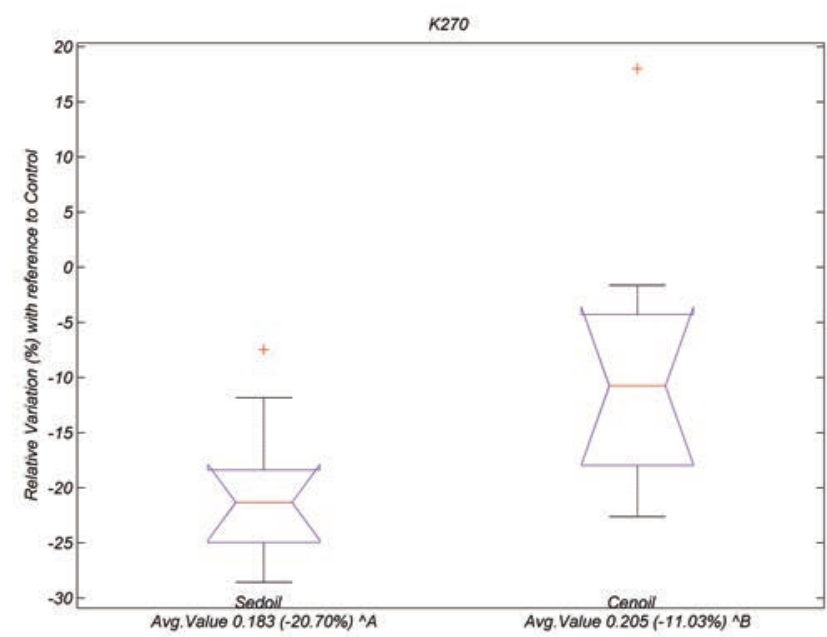

Figure 7. K270 values box plot of relative difference with reference to Control.

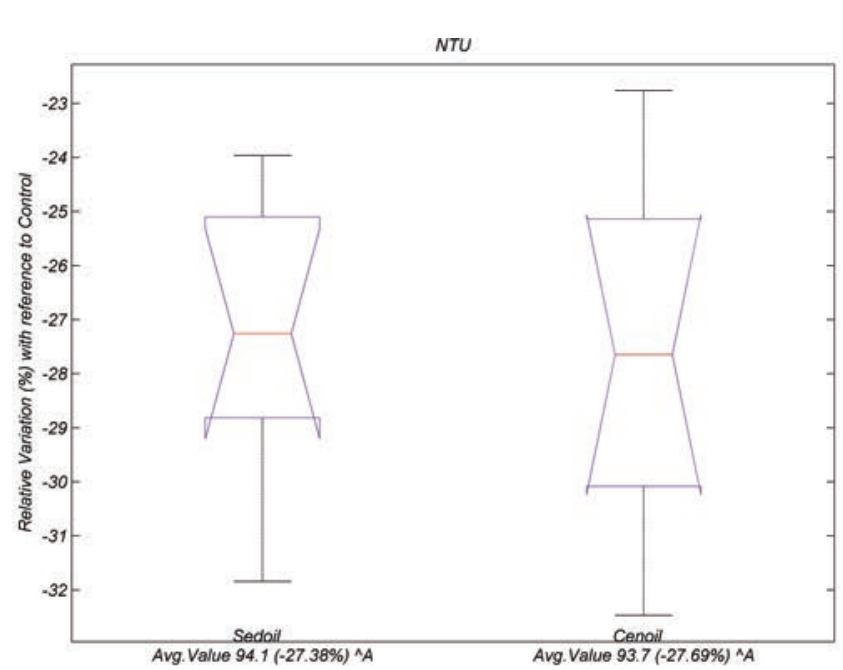

Figure 8. Turbidity values box plot of relative difference with reference to Control. 
Table 1. Kruskal-Wallis test on the relative differences respect to the reference treatment Control. Multiple comparison tests at $10 \%$ significance level. In the bracket the relative percentage variation. Same letter in each row means no significantly difference at stated significance level.

\begin{tabular}{lcccc} 
Parameter & Control & Sedoil & Cenoil & \\
Free acidity $[\mathrm{g} / \mathrm{l00} \mathrm{g}]$ & 0.34 & $0.28(-16.78 \%)^{\mathrm{a}}$ & $0.31(-7.57 \%)^{\mathrm{a}}$ & 0.724 \\
Peroxide value $[\mathrm{meq} / \mathrm{kg}]$ & 3.4 & $2.9(-16.15 \%)^{\mathrm{a}}$ & $3.9(14.63 \%)^{\mathrm{b}}$ & 0.001 \\
\hline Total polyphenols $\left[\mathrm{mg} / \mathrm{dm}^{3}\right]$ & 185.2 & $180.9(-2.35 \%)^{\mathrm{a}}$ & $171.2(-7.57 \%)^{\mathrm{b}}$ & 0.009 \\
Chlorophyll $[\mathrm{mg} / \mathrm{kg}]$ & 23.24 & $21.28(-8.43 \%)^{\mathrm{a}}$ & $14.44(-37.86 \%)^{\mathrm{b}}$ & 0.003 \\
\hline Carotenoid $[\mathrm{mg} / \mathrm{kg}]$ & 12.29 & $11.06(-10.00 \%)^{\mathrm{a}}$ & $8.87(-27.78 \%)^{\mathrm{b}}$ & 0.009 \\
K232 [AU] & 1.614 & $1.489(-7.72 \%)^{\mathrm{a}}$ & $1.693(4.89 \%)^{\mathrm{b}}$ & 0.001 \\
\hline K270 [AU] & 0.231 & $0.183(-20.70 \%)^{\mathrm{a}}$ & $0.205(-11.03 \%)^{\mathrm{b}}$ & 0.024 \\
Turbidity [NTU] & 129.6 & $94.1(-27.38 \%)^{\mathrm{a}}$ & $93.7(-27.69 \%)^{\mathrm{a}}$ & 0.825 \\
\hline Water content $\%$ & 3.0 & $0.9(-69.56 \%)^{\mathrm{a}}$ & $0.7(-76.51 \%)^{\mathrm{a}}$ & 0.566 \\
Temperature [ $\left.{ }^{\circ} \mathrm{C}\right]$ & 33.3 & $29.8(-10.42 \%)^{\mathrm{a}}$ & $34.0(2.10 \%)^{\mathrm{b}}$ & 0.000 \\
\hline
\end{tabular}

Nevertheless this behaviour is not general.

Figure from 1 to 8 show the box plot of relative variation (\%) of evaluated parameters in both Sedoil and Cenoil with reference to Control. Boxes represent the first quartile (q1), median and third quartile (q3) of the evaluated parameters, and lower (L) and upper (U) limits are defined as:

$\mathrm{L}=\mathrm{q} 1-1.5 \times \mathrm{IQR}$ and $\mathrm{U}=\mathrm{q} 3+1.5 \times \mathrm{IQR}$, where $\mathrm{IQR}=\mathrm{q} 3-\mathrm{q} 1$.

The average FA value of Sedoil and Cenoil did not differ significantly from Control, despite average FA value of Sedoil results lower than the other. The FA parameter is related to the hydrolytic enzymes activities in presence of water and with optimal temperature level in the range 30 to $40{ }^{\circ} \mathrm{C}$.

$\mathrm{PV}$ measures the formation of hydroperoxides in presence of oxygen pointing out the effect on the quality of the processing operation, in terms of oxygen contact with olive oil during the cleaning operation (Boskou, 2006).

In the olive oil samples of Cenoil the average PV results equal to 3.9 meq/kg significantly different from the average value of $2.9 \mathrm{meq} / \mathrm{kg}$ measured in Sedoil samples. Furthermore the Cenoil treatment increases the PV with respect to Control by $14.63 \%$, whereas Sedoil treatment lowers the PV value by $-16.15 \%$ showing a significantly increase in the oil quality.

This result confirms that the deep contact between oil and oxygen caused by the use of the disc stack centrifuge represents an important oxidative effect and the residual water in the oil is an additional source of oxidation.

POL average value observed in Sedoil was equal to $180,9 \mathrm{mg} / \mathrm{dm}^{3}$ and the difference resulted not significant from that observed for the Control $\left(185.2 \mathrm{mg} / \mathrm{dm}^{3}\right)$, but the average value measured in Cenoil $\left(171.2 \mathrm{mg} / \mathrm{dm}^{3}\right)$ resulted lower and the difference significant. Probably, considering the high water solubility of POL, the highest PV value found in Control samples could be related to an higher residual water content after the extraction performed by the decanter, that was found to be $3.0 \%$ respect to the water content of Sedoil and Cenoil equal to $0.9 \%$ and $0.7 \%$. CHLO, CAR, K232 and K270 in Sedoil were found to be significantly different respect to the Cenoil samples.

The TUR average value resulted 93.7 in Cenoil, lower than the average value of 94.1 measured in Sedoil, but the difference was not significant.

\section{Conclusions}

In this paper the authors describe the results on olive oil quality obtained in trials carried out to define the design parameters of a prototype system based on natural sedimentation to separate olive oil with highest quality in comparison with traditional centrifugal separation and raw oil (before cleaning operation). The experimental trials were carried out using a laboratory plant, based on a separating system constituted by a twin cylindrical oil-water separator, in order to define the design criteria of the innovative plant prototype, oil samples were collected and analyzed after the processing operations.

The separation system proposed by the authors allows achieving an efficient water separation and doesn't affect the olive oil temperature. The separation system had a significant effect on the chemical attributes of the olive oil: from the obtained results Sedoil was characterized by significant differences in POL, PV, CHLO, CAR, K232 and K270. No significant differences were found in FA e TUR.

Oil obtained by the innovative plant showed an higher POL content (180.9 mg/l vs. $171.2 \mathrm{mg} / \mathrm{l}$ ) and a lower PV (2.90 vs. 3.90). Considering the general increasing of olive oil quality induced by non-centrifugal final separation an innovative plant was designed using the collected data. Further investigation will be made to evaluate the shelf life of Sedoil after 3, 6 and 12 months, at last the industrial innovative plant will be designed.

\section{References}

Altieri G. 2010. Comparative trials and an empirical model to assess throughput indices in olive oil extraction by decanter centrifuge. Journal of Food Engineering. 97(1):46-56.

Amirante P., Catalano P. 1993. Analisi teorica e sperimentale dell'estrazione dell'olio d'oliva per centrifugazione. La rivista italiana delle sostanze grasse. LXX:329-335.

Amirante R., Catalano P. 2000. Fluid dynamic analysis of the solid-liquid separation process by centrifugation. Journal of Agricultural Engineering Research. 77 (2):193-201.

Boskou, D. Olive Oil: Chemistry and Technology. $2^{\text {th }}$. AOCS Publishing. 2006. 
Boncinelli P., Daou M., Cini E., Catalano P. 2009. A Simplified Model for Designing and Regulating Centrifugal Decanters for Olive Oil Production. Transactions of the ASABE, American Society of Agricultural and Biological Engineers. 52(6):1961-1968.

Catalano P., Pipitone F., Calafatello A., Leone, A. 2003. Productive efficiency of decanters with short and variable dynamic pressure cones. Biosystems Engineering 86 (4): 459-464.

Daou M., Furferi R., Recchia L., Cini E. 2007. A modelling approach to extra virgin olive oil extraction. Journal of Agricultural Engineering. 38(4):11-20.

Del Giovine L., Fabietti F. 2005. Copper chlorophyll in olive oils:identifi- cation and determination by LIF capillary electrophoresis. Food Control. 16:267-272.

Di Giovacchino L., Sestili S., Di Vincenzo D. 2002. Influence of olive processing on virgin olive oil quality. Eur J Lipid SciTechnol. 104:587-601.

Koidis A., Triantafillou E., Boskou D. 2008. Endogenous micro-flora in turbid virgin olive oils and the physicochemical characteristics of these oils. Eur J Lipid Sci Tech. 110:164-171.

Masella P., Parenti A., Spugnoli P., Calamai L. 2009. Influence of vertical centrifugation on extra virgin olive oil quality. J. Am. Oil Chem. Soc. 86:1137-1140. 